\title{
Single stage treatment of cholelithiasis and choledocholithiasis: Report of first cases with combined endoscopic and laparoscopic technique
}

\author{
Evren Dilektaşlı, ${ }^{1,2}$ Nizamettin Demirci, ${ }^{2}$ Mehmet Fatih Erol, ${ }^{2}$ Mehmet Emrah Bayam, ${ }^{2}$ \\ Deniz Tihan, ${ }^{2} \mathrm{Hacı}$ Murat Çaycı, ${ }^{2}$ Uğur Duman ${ }^{2}$ \\ 'Acute Care Surgery and Surgical Critical Care, Department of Surgery, Southern California University, California, USA \\ ${ }^{2}$ Department of General Surgery, Sevket Yilmaz Training and Research Hospital, Bursa, Turkey
}

\begin{abstract}
Introduction: There are still many controversies in the treatment of cholecysto-choledocholithiasis. When cholelithiasis is present with concomitant choledochus stone, both choledochus clearance and cholecystectomy have been advised in recent guidelines. However, the sequence and whether there should or should not be an interval between the 2 procedures is still debated.

Materials and Methods: Data of 10 patients who underwent endoscopic retrograde cholangio pancreatography $(E R C P)$ and laparoscopic cholecystectomy in same session between 2012 and 2013 were retrieved and analyzed.

Results: Feasibility of combination of procedures, under the same general anesthesia was examined.

Conclusion: Analysis of first 10 cases suggests that single session ERCP and laparoscopic cholecystectomy is safe and feasible means of managing cholecysto-choledocholithiasis. No increase in complication rate, operation time, or hospital stay was found.
\end{abstract}

Keywords: Cholecystectomy; endoscopic retrograde cholangio pancreatography; laparoscopy; same; session.

\section{Introduction}

Despite increased knowledge and improvements in surgical skill, cholelithiasis and concomitant choledochus stones are still a challenge for surgeons. New radiological devices with high-resolution images have increased preoperative diagnosis of these concomitant diseases. There are different strategies depending on the clinical experience and hospital resources. The most popular ones in our daily clinical basis are open cholecystecto- my with common bile duct (CBD) exploration, preoperative endoscopic retrograde cholangiopancreatography (ERCP) with early or delayed laparoscopic cholecystectomy (LC), laparoscopic cholecystectomy with laparoscopic CBD exploration (LCBDE) either using cystic duct or with an operative choledochotomy, "laparoendoscopic rendezvous" technique consisting the same session LC with intraoperative ERCP using a guide wire, and con- 
secutive ERCP and cholecystectomy under same anesthesia. ${ }^{[1-10]}$

\section{Materials and Methods}

From the patients admitted to Sevket Yilmaz Training and Research Hospital either with acute biliary pancreatitis with newly diagnosed or previously known cholelithiasis or with concomitant gallbladder and CBD stones between the years 2012 and 2013, ten patients were chosen to be operated with same session ERCP and cholecystectomy (SSEC). Consent forms were collected from all patients and the data of these patients were collected retrospectively and analyzed.

\section{Results}

In these ten patients, including eight female and two male patients, the median age was 58.5 years (IQR 54.25$62.75)$. Half of the patients had one or more comorbid diseases. Six patients admitted to the emergency department with different complaints were all referred to the general surgery department. After the initial assessment of the patients with ultrasonography findings and biochemistry results,acute biliary pancreatitis was diagnosed in five and cholecysto-choledocholithiasis in one patients. Patients were all hospitalized after diagnosis. Pancreas assessment was performed with computed tomography (CT) and radiological choledochus visualization was achieved with magnetic resonance cholangiopancreatography (MRCP). The remaining four patients were admitted to the general surgery department with jaundice and related symptoms. After the diagnosis of cholecysto-choledocholithiasis, the patients were hospitalized. In these four patients, MRCP was the radiological tool for verifying choledocholithiasis.

Patients were informed about the procedure in detail and informed consent forms were obtained. With preoperative fasting, on the day of the operation, anesthesia induction and intubation were achieved. Prone positioning was given and endoscopic retrograde cholangiopancreatography-endoscopic sphincterotomy (ERCP-ES) was performed primarily. ES was completed in all patients and choledochus calculus were cleared during the procedure in six patients. After ERCP-ES, patients were immobilized in supine position and conventional 4 port laparoscopic cholecystectomy was carried out. In all patients, cholecystectomy could be managed laparoscopically without any conversion. Median operative time was 75 minutes

\section{Table 1. Results}

Age, years

Gender (female/male)

ASA score

$58.5(54.25-62.75)$

$8 / 2$

$2(2-3)$

$75(59.5-83.5)$

$25.5(21.5-34.25)$

$49(36-53.5)$

$28.5(19.5-35.5)$

$2(2-3)$

$176.5(133.5-232.75)$
None
Mild Post-ERCP pancreatitis

(1 patient)

Age, years
Gender (female/male)
ASA score
Total time, min
ERCP time, min
Operation time, min
Estimated blood loss, cc
Hospital length of stay, days
Follow-up, days
Complications
Major
Minor

All results are presented as medians (IQR25-IQR75).

(IQR 59.5-83.5). All ERCP procedures were held by the same surgeon in the team experienced in ERCP procedures by performing more than 300 ERCP procedures per year. Laparoscopic cholecystectomy (LC) was performed by two surgeons in the team, both experienced in laparoscopic hepatobiliary system surgery. Median hospital stay was two days (IQR 2-3) and only one patient had a minor complication, mild post ERCP pancreatitis. That patient was also totally healed with appropriate medication. Mean follow-up time was 176.5 days (IQR 133.5-232.75) and in this period, no patient admission due to complications and the procedure occurred. Results are given in Table 1.

\section{Discussion}

For most surgeons, SSEC seems to be a logical procedure having some advantages when compared to other procedures. Regarding the two-step procedure, when ERCP is the first step after ERCP, if patients have new fallen stones from gall bladder to choledochus, ES prevents patients developing new complications. However, it is not so rare that even after ERCP-ES, in the waiting period for cholecystectomy, there could be new episodes of fallen stones to $\mathrm{CBD}$ with related complications like recurrent pancreatitis or cholangitis. Though there are reports in the literature of one-third of patients encountering recurrence within an interval of four to six weeks, which may increase with time, after ERCP, the waiting period for cholecystectomy varies from two to three days to four to six weeks in different institutions. ${ }^{[11-15]}$ There are even some studies for 
elderly patients with critical comorbid diseases about performing only ERCP, leaving gall bladder in-situ. ${ }^{[16]}$

By means of anesthesia related complications in one step procedure, SSEC seems to be superior to two-step procedure. It is shown that in propofol or benzodiazepine sedation, incidences of mild anesthesia-related complications is $2.3 \%$ and $2.4 \%$, respectively. ${ }^{[17]}$

Another advantage of performing SSEC during laparoscopic cholecystectomy is that the team can check simultaneously when there is a suspicion of iatrogenic complication related to ERCP. The risk of duodenal perforation has ranged from $0.37 \%$ to $0.58 \%$ in different studies. ${ }^{[18,19]}$ In SSEC, perforation can be diagnosed with or without methylene blue or air fluid tests. Early diagnosis of iatrogenic perforation and the chance of managing it in the same procedure could be a valuable and life saving opportunity.

There are also some controversies about SSEC. In surgical point of view, one could be suspicious about the course of the operation. Owing to the ERCP related intraduodenal gas, it is believed that visualization of the anatomic landmarks would be troublesome. However, in our clinical experience, when we experienced some problems on visualization with the nasogastric aspiration performed by the anesthesia team, the visualization of clinical landmarks improved totally. It should also be notified that we avoided giving too much gas when carrying out ERCP.

SSEC for common bile duct stones is an alternative to twostage ERCP and laparoscopic cholecystectomy and to onestage laparoscopic bile duct exploration. SSEC is a safe and effective strategy when dealing with cholecystocholedocholithiasis. It is our belief that it has many important advantages which includes avoiding a second anesthetic or sedation, not increasing the length of operation and hospital stay without an increase in conversion rates to open procedure. However, it is also our belief that more studies are needed on this topic before its routine usage in surgical practice is considered.

\section{References}

1. Ambreen M, Shaikh AR, Jamal A, Qureshi JN, Dalwani AG, Memon MM. Primary closure versus T-tube drainage after open choledochotomy. Asian J Surg 2009;32:21-5.

2. Pitt HA. Role of open choledochotomy in the treatment of choledocholithiasis. Am J Surg 1993;165:483-6.

3. Morino M, Baracchi F, Miglietta C, Furlan N, Ragona R, Garbarini A. Preoperative endoscopic sphincterotomy versus lap- aroendoscopic rendezvous in patients with gallbladder and bile duct stones. Ann Surg 2006;244:889-93.

4. Bonatsos G, Leandros E, Polydorou A, Romanos A, Dourakis $\mathrm{N}$, Birbas $\mathrm{C}$, et al. ERCP in association with laparoscopic cholecystectomy. A strategy to minimize the number of unnecessary ERCPs. Surg Endosc 1996;10:37-40.

5. Carr-Locke DL. Therapeutic role of ERCP in the management of suspected common bile duct stones. Gastrointest Endosc 2002;56:S170-4.

6. Zhu JG, Han W, Zhang ZT, Guo W, Liu W, Li J. Short-term outcomes of laparoscopic transcystic common bile duct exploration with discharge less than 24 hours. J Laparoendosc Adv Surg Tech A 2014;24:302-5.

7. Zhang WJ, Xu GF, Wu GZ, Li JM, Dong ZT, Mo XD. Laparoscopic exploration of common bile duct with primary closure versus T-tube drainage: a randomized clinical trial. J Surg Res 2009;157:e1-5.

8. Tzovaras G, Baloyiannis I, Kapsoritakis A, Psychos A, Paroutoglou G, Potamianos S. Laparoendoscopic rendezvous: an effective alternative to a failed preoperative ERCP in patients with cholecystocholedocholithiasis. Surg Endosc 2010;24:2603-6.

9. Jakobsen HL, Vilmann P, Rosenberg J. Endoscopic sphincterotomy for common bile duct stones during laparoscopic cholecystectomy is safe and effective. Surg Laparosc Endosc Percutan Tech 2011;21:450-2.

10. Bencini L, Tommasi C, Manetti R, Farsi M. Modern approach to cholecysto-choledocholithiasis. World J Gastrointest Endosc 2014;6:32-40.

11. Bismar HA, Al-Salamah SM. Outcome of laparoscopic cholecystectomy in acute biliary pancreatitis. Saudi Med J 2003;24:660-4.

12. Alimoglu O, Ozkan OV, Sahin M, Akcakaya A, Eryilmaz R, Bas G. Timing of cholecystectomy for acute biliary pancreatitis: outcomes of cholecystectomy on first admission and after recurrent biliary pancreatitis. World J Surg 2003;27:256-9.

13. Working Party of the British Society of Gastroenterology; Association of Surgeons of Great Britain and Ireland; Pancreatic Society of Great Britain and Ireland; Association of Upper GI Surgeons of Great Britain and Ireland. UK guidelines for the management of acute pancreatitis. Gut 2005;54 Suppl 3:iii19.

14. Uhl W, Müller CA, Krähenbühl L, Schmid SW, Schölzel S, Büchler MW. Acute gallstone pancreatitis: timing of laparoscopic cholecystectomy in mild and severe disease. Surg Endosc 1999;13:1070-6.

15. Mann K, Belgaumkar AP, Singh S. Post-endoscopic retrograde cholangiography laparoscopic cholecystectomy: challenging but safe. JSLS 2013;17:371-5.

16. Bignell $M$, Dearing $M$, Hindmarsh $A$, Rhodes M. ERCP and endoscopic sphincterotomy (ES): a safe and definitive management of gallstone pancreatitis with the gallbladder left in situ. J Gastrointest Surg 2011;15:2205-10.

17. Lordan JT, Woods J, Keeling P, Paterson IM. A retrospective analysis of benzodiazepine sedation vs. propofol anaesthe- 
sia in 252 patients undergoing endoscopic retrograde cholangiopancreatography. HPB (Oxford) 2011;13:174-7.

18. Coppola R, Riccioni ME, Ciletti S, Cosentino L, Coco C, Magistrelli $\mathrm{P}$, et al. Analysis of complications of endoscopic sphincterotomy for biliary stones in a consecutive series of 546 pa- tients. Surg Endosc 1997;11:129-32.

19. Loperfido S, Angelini G, Benedetti G, Chilovi F, Costan F, De Berardinis $F$, et al. Major early complications from diagnostic and therapeutic ERCP. a prospective multicenter study. Gastrointest Endosc 1998;48:1-10. 